\title{
How safe are metal-on-metal hip implants?
}

\author{
Deborah Cohen examines the evidence of risk from metal-on-metal hips, the manufacturers' \\ inadequate response, and how the regulatory bodies failed to give doctors and patients the \\ information they need to make informed decisions
}

\section{Deborah Cohen investigations editor}
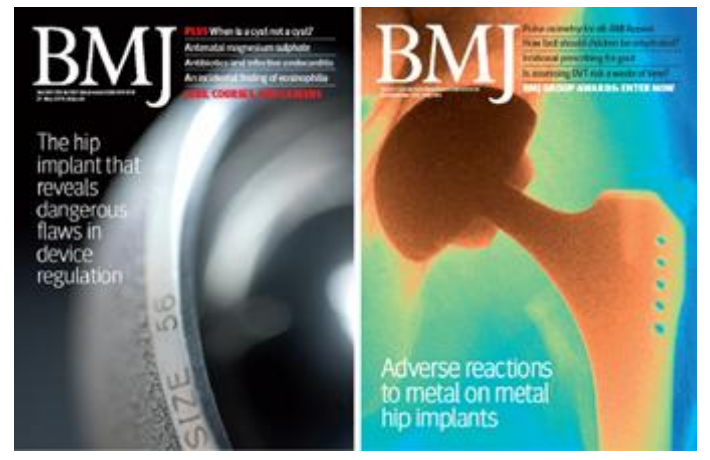

Hundreds of thousands of patients around the world may have been exposed to toxic substances after being implanted with poorly regulated and potentially dangerous hip devices, a $B M J /$ BBC Newsnight investigation reveals this week. Despite the fact that these risks have been known and well documented for decades, patients have been kept in the dark about their participation in what has effectively been a large uncontrolled experiment.

This isn't the unlucky failure to spot the misdemeanours of one rogue company or the occasional unforeseen breakdown of a small number of devices. It is the inability to prevent a whole class of failing hip implant from being used in hundreds of thousands of people globally - a class of implant that the usually reticent National Joint Registry of England and Wales described recently as a "cause for concern." 12 The implants concerned are "metal on metal"- the head at the top and the lining of the cup it fits into are made of cobalt-chromium alloy rather than ceramic or polyethylene- and there are models for both total hip replacement and hip resurfacing.

From their arrival on the orthopaedic scene in 1997, they were marketed as the latest advance in hip replacement and were targeted at young active patients who needed a hip that would last a whole lifetime. And while there is evidence that hip resurfacing works well in young active men, ${ }^{3}$ the failure rates of resurfacing in women and of metal-on-metal total hip replacements in both sexes are higher than they should be. Average failure rates at seven years are $11.8 \%$ for resurfacing and $13.6 \%$ for metal-on-metal total hip replacement, although failure rates vary with the brand used. This compares with rates of $3.3 \%-4.9 \%$ for hip implants made of other materials. ${ }^{2}$

Metal-on-metal devices have been implanted into over 60000 patients in England and Wales since 2003-when the National Joint Registry first began to record procedures. Before this date numbers are unreliable. In the US the figure is closer to a million and likely to increase. At the annual American Academy of Orthopedic Surgeons conference in February this year, a roll call of manufacturers was still promoting these products to the 40000 attendees in the exhibitor hall.

Cobalt-chromium implants have been used successfully in orthopaedics for years-for example, in knee operations and fracture repair. They are known to release metal ions, but some metal-on-metal prostheses do so on a much greater scale than previously thought. These ions can seep into local tissue causing reactions that destroy muscle and bone and leaving some patients with long term disability. ${ }^{4}$ Local tissue reactions associated with ions from metal-on-metal hips were first described in detail as long ago as $1975 .{ }^{5}$ The ions can also leach into the bloodstream spreading to the lymph nodes, spleen, liver, and kidneys before being excreted in urine. ${ }^{6}$

\section{Metal ions and genotoxicity}

Multiple studies and research organisations have warned about the carcinogenic potential of metal-on-metal hips. ${ }^{7}$ That cobalt and chromium ions lead to genotoxic changes both in laboratory settings and in animals was described in scientific journals over 30 years ago. ${ }^{8}$ Cobalt too was shown to be linked to cardiomyopathy in $1966 .{ }^{9}$ However, the link to cancer is not proved.

In 1990, the World Health Organization International Agency for the Research on Cancer released a monograph listing 
hexavalent chromium as a proved carcinogen; trivalent chromium a potential carcinogen; and cobalt ions a probable carcinogen. $^{10}$

Only recently_after the early failure of thousands of implants-have tests from the London Implant Retrieval Centre, a centre that tests prostheses, confirmed that trivalent chromium is the ion being released. ${ }^{11}$

The manufacturers were aware of the potential for genotoxicity. The BMJ and Newsnight have seen a DePuy internal memo from July 2005, that says: "In addition to inducing potential changes in immune function, there has been concern for some time that wear debris may be carcinogenic. The mechanism is not known and only 24 local malignancies have been reported in patients with joint replacements. Also worrying is the possibility of distant effects. One study suggested a threefold risk of lymphoma and leukaemia 10 years after joint replacement. The metal to metal total hip appears to be quite promising and in the laboratory the data is (sic) definitely in its favour. However, the ultimate test is the long term human experience."

Despite this uncertainty, DePuy's marketing of metal-on-metal hips continued unabated, with promotional material failing to reflect internal company concerns. Instead, in 2006 the sales teams were equipped with a paper entitled, "Setting the record straight on metal hypersensitivity," written by one of DePuy's prosthesis designers, Los Angeles orthopaedic surgeon Thomas Schmalzried, to counter emerging concerns on the topic.

Meanwhile the UK's Committee on Mutagenicity of Chemicals in Food, Consumer Products and the Environment started to have concerns about the carcinogenic potential of metal-on-metal hip implants. ${ }^{12}$ In response, the Medicines and Healthcare Products Regulatory Agency (MHRA) convened a meeting in March 2006 to discuss the long term health effects.

The agency knew this was a sensitive topic. The minutes describe how the chairman stressed the importance of confidentiality before the paper was presented and that "anyone who felt they were unable to keep this matter completely confidential was asked to leave the room." No-one left. ${ }^{12}$

The MHRA discussed the problem with the Department of Health's Committee on Mutagenicity. In July that year (2006), the committee concluded that "there is evidence to suggest that some metal-on-metal (those using cobalt-chromium) hip replacements may be associated with increased DNA-changes, and increased genotoxicity in patients. It said this: "gave rise to concern because this may present a potential risk of carcinogenicity in humans. ${ }^{13}$ But it concluded that the clinical implications were uncertain.

To try to establish the risks posed by metal-on-metal implants, the MHRA subsequently appointed an expert advisory group. Of the group's eight members, three had conflicts of interest: two were DePuy consultants and one was the director of product development for Smith and Nephew. The group's brief was to put metal hips "into a risk-benefit context." There was no statistician or epidemiologist in the group.

In the face of such hazard and uncertainty, the group could have warned against the use of metal-on-metal hips, which had not been shown in comparative trials to be better than conventional hips. According to the minutes of the first meeting in October 2006, Patrick Case, a senior lecturer in orthopaedic surgery and pathology, said: "Surgeons have a choice of which [prosthesis] to implant." Instead, the minutes highlighted the benefits of metal-on-metal implants for resurfacing and total hip replacement. The group did not heed the advice of Derek McMinn, designer of Smith and Nephew's Birmingham Hip
Resurfacing (BHR) implant. He had published a paper in the UK's main orthopaedics journal, the Journal of Bone and Joint Surgery, in 2004 concluding: "Caution still needs to be exercised until longer term results are available.",

Nor did it choose to contraindicate metal-on-metal hips in women of child bearing age — even though metal ions had been detected in umbilical cord and placental blood. Instead the group criticised the US Food and Drug Administration, which had contraindicated this use, for an unclear risk analysis. ${ }^{15}$

As a result of the group's advice, the MHRA's Committee on Safety of Devices concluded in July 2007 that patients should sign a consent form "which sets out the fact that the risks associated with metal wear debris have been discussed, including the genotoxic risk and possible sequelae." The committee wanted to "ensure patients know there is a risk now and sign consent if necessary," minutes say. ${ }^{16}$

But this requirement was not communicated widely—no alert was put out to surgeons or patients.

According to Tony Nargol, an orthopaedic surgeon at University Hospital of North Tees, surgeons were unaware of these discussions.

Data that the National Joint Registry supplied to the $B M J$ show implantation rates peaked in the following two years, and over 20000 large diameter metal-on-metal hips alone were implanted thereafter.

Only in March 2011 did the British Orthopaedic Association warn that large diameter metal-on-metal total hip replacements should be "carefully considered and possibly avoided."17

Nor did the MHRA require companies to start proper post-approval studies. Although epidemiological studies have not found a link with cancer, ${ }^{18}$ they may not reflect the current reality. The metal hips currently being implanted are different in design to earlier models on which the studies were based, and since metal on metal has primarily been used in younger people, patient demographics have also changed. The $B M J$ is aware of one UK case series that is due to report next month.

\section{Uncertain risks from metal ions}

Uncertainty surrounds the toxicology of metal ions in the body. As a commentary in the Lancet in 2007 said: "Little is known about the transport, distribution, and excretion of metal ions in the body," adding "toxic effect thresholds have not been characterised." 19

Nick Freemantle, professor of clinical epidemiology and biostatistics at University College London, suggests this level of uncertainty would not be acceptable in drug regulation. "If it was the pharmaceutical industry developing a new chemical entity, it would be abandoned early on if it metabolised in the wrong bits of the liver," Professor Freemantle says. "We shouldn't be in this position where we don't know and there's so much uncertainty. The stability of a compound should have been ascertained before it was used widely in people. As yet, we don't know the consequences of this."

There are no guidelines on what constitutes an unacceptably high level of cobalt ions in blood for patients receiving orthopaedic implants..$^{19}$ DePuy's designer and consultant, Dr Schmalzried, has said that, in patients with a well functioning device, levels should be no higher than $2 \mu \mathrm{g} / \mathrm{L} .{ }^{20}$ However, he may have seen this as a marker for device failure rather than in relation to safe levels of metal ions in the patient's blood.

In fact, studies show that blood cobalt concentrations generated through the wear of some of the newer metal-on-metal total hip 
prostheses can reach over $300 \mu \mathrm{g} / \mathrm{L}$ - higher than anything routinely documented in the past. This is 600 times higher than physiological levels of cobalt-most healthy people have about $0.5 \mu \mathrm{g} / \mathrm{L}$ of cobalt in their blood. ${ }^{21}$ According to the MHRA, patients should be investigated above a threshold level of 7 $\mu \mathrm{g} / \mathrm{L},{ }^{22}$ although it is unclear what this figure is based on or how it was derived.

Metal ion levels above this level have been recorded in around $20 \%$ of patients (range 5-22\%) with some metal-on-metal prostheses-such as DePuy's flagship Pinnacle hip system. ${ }^{23-25}$ Over 300000 Pinnacle prostheses have been put in worldwide.

Data showing raised metal ions in people with the Pinnacle have been available in the medical literature since $2008,{ }^{23}$ yet the device formed a key part of DePuy's main hip strategy in 2009, as internal emails show. Pinnacle was promoted as "an alternative for the majority of patients" when the ASR implants were recalled globally in 2010 . The Pinnacle is not the only metal-on-metal implant causing increased metal ion concentrations. A two year follow-up study published in May 2011 shows an incremental increase in metal levels in 144 patients with large head metal-on-metal implants made by companies including Zimmer, DePuy, and Smith and Nephew. ${ }^{26}$ Other studies have shown raised ions with Smith and Nephew's Birmingham total hip replacement (range 1.2-14.2 $\mu \mathrm{g} / \mathrm{L}, 20 \%>7$ $\mu \mathrm{g} / \mathrm{L}),{ }^{27}$ Zimmer's Durom total hip replacement (range 1-12 $\mu \mathrm{g} / \mathrm{L}){ }^{28}$ and ASR-XL total hip replacement $(0.7-217 \mu \mathrm{g} / \mathrm{L}){ }^{29}$

Also problematic are the smaller hip resurfacing implants, which are used in women and smaller men. Because these implants lubricate less well, they produce metal debris and high metal concentrations in the blood. In the largest published series, 5\% of 343 people, and $17.8 \%$ of those with a small Birmingham hip resurfacing, were found to have blood cobalt concentrations above $7 \mu \mathrm{g} / \mathrm{L} .^{30}$

\section{Tweaking the design}

Instead of alerting regulators and patients to their concerns, companies tweaked the design of their total hip implants. In 2004, in an effort to rationalise their product range and increase usage of their implants, they shortened the trunnion (or taper) - the part of the stem that inserts into the head - to allow a few degrees greater motion and added grooves so surgeons could use them with both ceramic and metal heads.

A recent Zimmer advertisement for the Spotorno stem, used as part of a metal-on-metal total hip replacement, describes design modifications to the stem. "In order to increase the range of motion and reduce impingement, the length of the taper has been shortened and the neck diameter has been reduced," it says.

But these changes, coupled with bigger and bigger heads, had unforeseen consequences: increased wear, high levels of metal ions in the tissues and blood, and higher rates of joint failure. Even a small change in design can have a substantial effect on long term outcome, as teams from Newcastle University and the London Implant Retrieval Centre have found. Using a complex algorithm on a coordinate measuring machine, they have measured the wear of these metal heads to see how damaged they become.

"We think that over the years these taper connections have just become shorter and shorter at the same time as the heads have become bigger and bigger. And we believe, it's just a leverage effect that's causing toggling and the joint to waggle," says Tom Joyce a biomedical engineer specialising in the design and evaluation of artificial joints at Newcastle University.
They found that where the head joins the stem the inside becomes blackened because the metal has worn away. The amounts are tiny-equivalent to a pinhead. But the consequences can be devastating.

"We're seeing patients with tapers which are blackened, destroyed, metal getting into the tissues of the hip, damaging the muscles, taking out some of the bone, so destroying parts of the pelvis," Mr Nargol says.

He adds that surgeons were unaware of the changes when companies implemented them. Indeed, some new implants by Zimmer and DePuy were marketed on the fact that their stems had remained unchanged over time using data from the previous unmodified model.

Far from being confined to a few prostheses, such risky design tweaks seem to be industry wide and on a scale that may be far greater than previously reported. And it seems that industry leaders are fully aware of the scale of issue. In a June 2010 internal email seen by the $B M J$, a senior figure in DePuy writes: "I feel the problem [with large diameter metal on metal] is emerging as more serious than first thought."

DePuy had been contacted in 2009 by Japanese surgeons with concerns about the Pinnacle metal hip system, as an internal DePuy email shows. The surgeons reported seeing "generated metal debris between stem taper and head, and final necrosed tissue" and blamed it on the poor connection between the two. Perhaps most worryingly, DePuy's senior engineers were still trying to figure out why the implants were failing in 2010 - over five years after the design changes had occurred. DePuy enlisted the help of Southampton University to conduct an in-depth investigation. But they did not tell surgeons to stop using their product while they investigated the matter.

\section{Regulatory failure}

But the regulators in Europe and the US failed to identify the design changes and their consequences for patient safety. "It's intrinsically tricky to know when you have a different device. Regulators find this very difficult to spot. But it can't be the decision of the manufacturer when they need more scrutiny," says Professor Freemantle.

Indeed, the shortening of one of DePuy's trunnions was cleared by the FDA in December 2004 with the comment: "The design, while not identical to the predicates, does not raise any new issues of safety or effectiveness." 31

The MHRA were first made aware of the problems in 2011, through emails from Mr Nargol. The agency asked for more information. "Clearly you have an issue with the DePuy taper, but you have said this is a generic problem across orthopaedics and that many companies changed their trunion (sic) design around 2005. Could you point us towards any of the other implants that have had these trunion (sic) changes so that we know which ones to look at?"

But regulatory failure started much earlier than this. When the devices were launched in Europe in 1997 directives placed hip implants into a category of device that required only simulator testing - a process that puts the hip through cycles of mechanical testing — which even DePuy acknowledged at the time was not the "ultimate" test.

"The fact that the entire system is based on device safety and functionality, with no efficacy requirement is also very surprising when it is applied to invasive treatment technology with significant inherent risk potential," Peter McCullough a reader in surgery at Oxford University has said. 


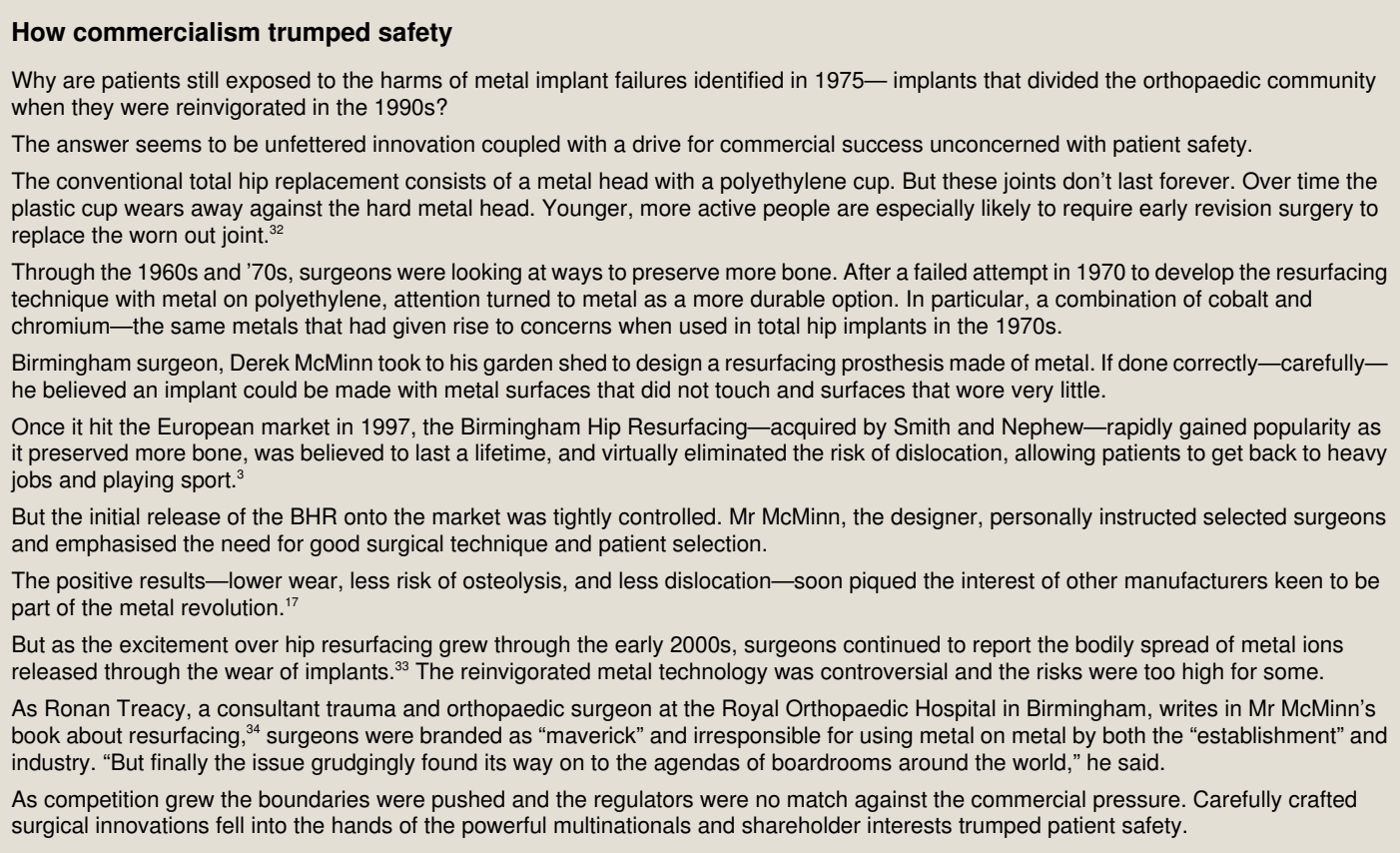

In the US, the FDA considered that the parts of metal-on-metal total hip replacements to be like other heads, cups, and stems already in use. This meant that the devices could be cleared through a less rigorous process, called 510(k), which requires no clinical studies to show how well these large heads worked when coupled with a modified stem.

"This is one very large uncontrolled experiment exposing millions of patients to an unknown risk. We will only find out about the safety of these devices after large numbers of people have already been exposed," says Michael Carome, deputy director of Public Citizen's Health Research Group, a US not for profit consumer advocacy group.

The FDA started to clear larger heads for market use in 1998 and by the end of 2010 had approved 175 implants through the $510(\mathrm{k})$ route.

And so a whole new class of implant—with the potential to release high concentrations of toxic ions-was launched onto the US and European markets without the need to conduct clinical trials and without any long term post-marketing studies.

But resurfacing was a new technique and so, in the US at least, the implants had to go through the FDA's more rigorous premarket approval process. This requires manufacturers to submit their product to clinical testing to prove it is both safe and-unlike the European process-effective for its intended use. It was this premarketing approval process that stopped DePuy's failing ASR resurfacing prosthesis coming to market, ${ }^{17}$ although the ASR XL total hip replacement was passed through the $510(\mathrm{k})$ route.

An international product manager for DePuy responded to similarly lax regulation in South Africa with an email to colleagues in June 2007 saying, "You could literally implant a tent rod if you wanted!"

Clinical trials achieved some changes of heart. A trial published in 2011 comparing large diameter metal-on-metal with conventional hip replacements made by Smith and Nephew was stopped after two years as $20 \%$ patients in the metal-on-metal group had raised metal ion concentrations in the blood. ${ }^{27}$

However, such data had little effect on patient safety. According to Chris Bulstrode, an orthopaedic surgeon at Oxford University, when he tried to warn the Department of Health about overzealous innovation, there was no appetite for determining effectiveness in trials. At a meeting with the implants division of the Department of Health in the early 1990s, Mr Bulstrode maintains the director didn't want to hear of problems. "There was no interest in blocking good British inventiveness, and there were no techniques apart from careful and prolonged follow-up to find out if these implants were better than the well-proven Charnley [a conventional implant]. It would have taken a minimum of 10 years and no-one had time for that when marketing departments were baying for new product," he said.

\section{Post-marketing surveillance}

That the high levels of metal ions produced by the modified devices were not picked up by either the European or American regulators on market entry is a cause for concern.

So too is the fact that the regulators mandated no post-approval studies requiring careful follow-up of patients implanted with devices capable of producing toxic debris. Instead, the only follow-up data came from ad-hoc studies by individual research teams.

The FDA has now decided to gather and review all available information about currently marketed metal-on-metal hip systems, including information related to adverse events that may be associated with increased levels of cobalt and chromium in the bloodstream. ${ }^{35}$

To that end in May 2011 the FDA wrote to about 20 manufacturers to say that it was invoking a rule requiring post-marketing studies in cases where an implant's failure could have serious consequences. Companies would be expected to take blood samples from patients to measure metal ions. They are also taking a decision on the classification of hip prostheses and how they should be regulated in future. As yet, the MHRA has taken no such action.

According to meeting minutes it is trying to link up the National Joint Registry with the National Cancer Registry. But experts argue this no proxy for post-marketing surveillance. ${ }^{18}$ 


\section{Regulatory role of Europe's "notified bodies"}

DePuy's Pinnacle large diameter metal-on-metal implants obtained certificates of safety and performance in 2009 and 2010 despite the emerging concerns. This enabled the Pinnacle to display a CE mark and be sold in Europe.

To get the CE mark, DePuy turned to the British company, BSI, one of several so called "notified bodies" that assess devices for European regulation. Internal documents show that regulatory managers in DePuy UK believed they had a good working relationship with BSI-although they said in 2008 that BSI were asking tougher questions. Nevertheless, unlike in the US, European regulation doesn't require clinical trials even for the highest risk device class, which hip implants now fall under. It is unclear to what extent BSI took account of concerns about basic design flaws and metal toxicity, all of which were well known to DePuy. The BMJ asked BSI if it knew of these concerns when it approved the Pinnacle implant. It declined to comment, saying it was "bound by strict obligations of confidentiality to our clients."

Meanwhile MHRA chief executive, Kent Woods, said publicly on 17 February 2012 on BBC Radio 4's flagship news programme, Today, that he has faith in the notified bodies.

Others are less sanguine. Peter McCullogh, a reader in surgery at Oxford University, says there are potential hazards in the current system. "The EU system of approval by agreement between manufacturer and a commercial regulatory body, under conditions of almost total commercial secrecy, overseen in a "hands off" manner by national regulatory authorities, seems extraordinary in its lack of transparency and the obvious inherent risks of collusion," he says.

\section{Conclusion}

After a series of failures, device regulation is in need of radical change. For its part, the FDA has decided to place all hip implants into a high risk category—fast track entry will be forbidden.

In Europe there is little doubt the current system is not fit for purpose and talks are underway about how to improve it. As Professor Freemantle asks: "Why is it that people are afforded different levels of protection depending on whether they have a heart attack, diabetes, or a hip replacement in their old age? The methods of device regulation seem to be more from the 1950 s than the 21 st century."

\section{Competing interests: None declared.}

Provenance and peer review: Commissioned; externally peer reviewed.

1 National Joint Registry of England and Wales. 8th annual report. 2011. Access link here. 2 Cohen D. Revision rates for metal on metal hip joints are double that of other materials. BMJ 2011;343:d5977.

3 Daniel J, Pynsent PB, McMinn DJ. Metal-on-metal resurfacing of the hip in patients under the age of 55 years with osteoarthritis. J Bone Joint Surg Br 2004;86:177-84.

4 Grammatopolous G, Pandit H, Kwon YM, Gundle R, McLardy-Smith P, Beard DJ, et al. Hip resurfacings revised for inflammatory pseudotumour have a poor outcome. J Bone Joint Surg Br 2009;91:1019-24.

5 Jones DA, Lucas HK, O'Driscoll M, Price CH, Wibberley B. Cobalt toxicity after McKee hip arthroplasty. J Bone Joint Surg Br 1975;57:289-96.

6 Case CP, Langkamer VG, James C, Palmer MR, Kemp AJ, Heap PF, et al. Widespread dissemination of metal debris from implants. J Bone Joint Surg Br 1994;76:701-12.

7 Ladon D, Doherty A, Newson R, Turner J, Bhamra M, Case CP. Changes in metal levels and chromosome aberrations in the peripheral blood of patients after metal-on-metal hip arthroplasty. J Arthroplasty 2004;19(suppl 3):78-83.

8 Freeman MA, Swanson SA, Heath JC. Study of the wear particles produced from cobaltchromium-molybdenum-manganese total joint replacement prostheses. Ann Rheum Dis 1969;28(suppl):29.

9 Barceloux D. Cobalt. J Toxicol Clin Toxicol 1999;37:201-16.

10 International Agency for Research on Cancer. IARC monographs supplement 7. 1990. Access link here.

11 Hart AJ, Quinn PD, Sampson B, Sandison A, Atkinson KD, Skinner JA, et al. The chemical form of metallic debris in tissues surrounding metal-on-metal hips with unexplained failure. Acta Biomater 2010;6:4439-46.

12 MHRA. Minutes of the Committee on the Safety of Devices meeting, March 2006. Access link here.

13 Committee of Mutagencity of Chemicals in Food, Consumer Products and the Environment. Statement on biological effects of wear debris generated from metal on metal bearing surfaces: evidence for genotoxicity. COM/06/S1. 2006. Access link here.

14 MHRA. Minutes of the Committee on the Safety of Devices expert advisory group on metal wear debris from hip implants, 23 October 2006. Access link here.

15 MHRA. Minutes of the Committee on the Safety of Devices expert advisory group on metal wear debris from hip implants, 24 April 2007. Access link here.

16 MHRA. Minutes of the Committee on the Safety of Devices meeting, 5 July 2007. Access link here.

17 Cohen D. Out of joint: the story of the ASR. BMJ 2011;342:d2905

18 Heneghan C, Langton D, Thompsom M. Ongoing problems with metal-on-metal hip implants. BMJ 2012;344:e1349.

19 Learmonth ID, Case CP. Metallic debris from orthopaedic implants. Lancet2007:369:542-4.

20 Cobb AG, Schmalzried TP. The clinical significance of metal ion release from cobalt chromium metal on metal hip joint arthroplasty. Proc Inst Mech Eng 2006;220:385-98.

21 Engh CA Jr, MacDonald SJ, Sritulanondha S, Thompson A, Naudie D, Engh CA. John Charnley award: metal ion levels after metal-on-metal total hip arthroplasty: a randomized trial. Clin Orthop Relat Res 2009;467:101-11.
22 MHRA. Medical device alert: all metal-on-metal (MoM) hip replacements. MHRA, 2010.

23 Antoniou J, Zukor DJ, Mwale F, Minarik W, Petit A, Huk OL. Metal ion levels in the blood of patients after hip resurfacing: a comparison between twenty-eight and thirty-six-millimeter-head metal-on-metal prostheses J Bone Joint Surg Am 2008;90(suppl 3):142-8

24 Fricka K, Engh CA, Hamilton WG, Ho H. Survivorship and revision analysis among primary metal on metal total hip arthroplasty using $36 \mathrm{~mm}$ diameter heads. Presentation at American Academy of Orthopedic Surgeons annual meeting, San Francisco, 9 Feb 2012

25 Takamua KM, Langton D, Ghandi JN, Nargol A, Joyce T, Lord J, et al. The main issue of large diameter MoM total hip arthroplasty: the taper junction. Presentation at American Academy of Orthopedic Surgeons annual meeting, San Francisco, 9 Feb 2012.

26 Lavigne M, Belzile EL, Roy A, Morin F, Amzica T, Vendittoli P-A. Comparison of whole-blood metal ion levels in four types of metal-on-metal large diameter femoral head total hip arthroplasty: the potential influence of the adapter sleeve. J Bone Joint Surg Am 2011:93:128-36

27 Malviya A, Ramaskandhan JR, Bowman R, Hashmi M, Holland JP, Kometa S, et al. What advantage is there to be gained using large modular metal-on-metal bearings in routine primary hip replacement? A preliminary report of a prospective randomised controlled trial. J Bone Joint Surg Br 2011;93:1602-9.

28 Garbuz DS, Tanzer M, Greidanus NV, Masri BA, Duncan CP. The John Charnley award: metal-on-metal hip resurfacing versus large-diameter head metal-on-metal total hip arthroplasty: a randomized clinical trial. Clin Orthop Relat Res 2010;468:318-25.

29 Langton DJ, Jameson SS, Joyce TJ, Gandhi JN, Sidaginamale R, Mereddy P, et al. Accelerating failure rate of the ASR total hip replacement. J Bone Joint Surg Br 2011;93:1011-6.

30 Langton DJ, Joyce TJ, Mangat N, Lord J, Van Orsouw M, De Smet K, et al. Reducing metal ion release following hip resurfacing arthroplasty. Orthop Clin North Am 2011;42:169-80, viii.

31 FDA. 510(k) Summary of safety and effectiveness. Access link here.

32 Schmalzried TP, Shepherd EF, Dorey FJ, Jackson WO, de la Rosa M, Fa'vae F, et al. The John Charnley award. Wear is a function of use, not time. Clin Orthop Relat Res 2000;381:36-46.

33 Urban RM, Jacobs JJ, Tomlinson MJ, Gavrilovic J, Black J, Peoc'h M. Dissemination of wear particles to the liver, spleen, and abdominal lymph nodes of patients with hip or knee replacement. J Bone Joint Surg Am 2000;82:457-77.

34 Treacy R. Foreword. In McMinn D. Modern hip resurfacing. Springer, 2009.

35 FDA. Metal-on-metal implants: FDA's role and activities. Access link here.

Cite this as: BMJ 2012;344:e1410

\section{Related links}

\section{bmj.com/archive}

- News: UK medical device regulation is criticised as both cumbersome and inadequate (2012;344:e1202)

- Practice: Diagnosing and investigating adverse reactions in metal on metal hip implants (2011;343:d7441)

- Research: Comparative assessment of implantable hip devices with different bearing surfaces: systematic appraisal of evidence $(2011 ; 343: \mathrm{d} 7434)$

- Feature: Europeans are left to their own devices (2011;342: d2748)

- Feature: Out of joint: the story of the ASR (2011;342: d2905)

(c) BMJ Publishing Group Ltd 2012 


\section{Timeline: Metal-on-metal hips}

1975: Study describeslocal tissue reactions caused by cobalt and chromium ions from metal-on-metal hips ${ }^{6}$

1988: Study shows human synoviocytes killed by cobalt in vitro (Rae T. Clin Orthop 1988;232:244-54)

1989: Metal-on-metal hip resurfacing designs start in Birmingham

1990: WHO International Agency for the Research on Cancer lists trivalent chromium as a potential carcinogen and cobalt ions as a probable carcinogen

1991: First metal-on-metal hip resurfacing device is implanted in Birmingham

1994: Study shows dissemination of cobalt and chromium ions into lymph, liver, and spleen ${ }^{5}$

1996: Patients with metal-on-metal hips found to be at increased risk of cancer compared with those with metal-on-plastic hips: relative risk of haematopoietic cancer 1.59 (95\% confidence interval 0.8 to 2.8) and leukaemia 3.77 (0.9 to 17.6) (Visuri T, et al. Clin Orthop 1996;329

(suppl):S280-9)

1997: Birmingham Hip Resurfacing (BHR) implant comes onto the European market

1998: Particles of cobalt and chromium shown to be toxic to monocytes in culture (Haynes DR, et al. Clin Orthop 1998;352:223-30)

2000: NICE guidance on selection of prostheses for primary hip replacement and resurfacing sets a benchmark revision rate for conventional hip replacement of $\leq 10 \%$ at 10 years

2003: Derek McMinn and Ronan Treacy publish paper showing positive results with BHR. This kickstarts the trend for larger heads in total hip replacement

2004 McMinn, designer of the BHR, says, "Caution still needs to be exercised until longer term results are available"

2004 One of DePuy's modified stems with a shortened trunnion is cleared by the FDA, which says the modified design "does not raise any new issues of safety or effectiveness"

2005: Internal DePuy memo reflects early concerns about health risks of wear debris from metal on metal hips. "In addition to inducing potential changes in immune function, there has been concern for some time that wear debris may be carcinogenic"

2006: MHRA Committee on Safety of Devices says there's growing concern over the biological risks of metal wear debris

2006: The Department of Health's Committee on Mutagenicity concludes that "some metal on metal (those using cobalt-chromium) hip replacements may be associated with increased DNA-changes, and increased genotoxicity in patients." It says this "may present a potential risk of carcinogenicity in humans"

2007: Implantation of large diameter metal-on-metal hips starts to increase rapidly in the UK, and resurfacing peaks. Metal-on-metal hips account for $20 \%$ of market this year

2007: UK expert advisory group chooses not to contraindicate metal-on-metal hips in women of child bearing age-even though metal ions had been detected in the umbilical cord and placental blood

2007: The MHRA's Committee on Safety of Devices recommends that all patients sign a consent form setting out the risks associated with metal wear debris. But this recommendation is not widely communicated

2008: Study shows $20 \%$ of patients with DePuy's Pinnacle hip system have metal ion levels over the upper limit accepted by occupational health experts

2009: Japanese surgeons raise concerns with the design of DePuy's large diameter metal-on-metal system. They report seeing "generated metal debris between stem taper and head, and final necrosed tissue" and blame it on the poor connection between the two

2009: All joint replacement implants are re-classified as class III devices after the implementation of Directive 2005/50/EC

2010: In an internal email obtained by the $B M J$, a senior figure in DePuy writes: "I feel the problem [with large diameter metal on metal] is emerging as more serious than first thought."

2010: DePuy recalls its ASR hip prostheses. Some studies show a failure of the total hip replacement secondary to adverse reactions to metal debris of $50 \%$ at 6 years

2010: DePuy promotes Pinnacle—including metal-on-metal—as "an alternative for the majority of patients"

2011: Tony Nargol and his team warn the MHRA of failures with the Pinnacle implants

2011: British Orthopaedic Association writes to surgeons to say that large diameter metal-on-metal total hip replacements should be "carefully considered and possibly avoided"

2011: A two year follow-up study in 144 patients shows an incremental increase in metal levels over the study period in a range of large head metal-on-metal implants made by companies including Zimmer, DePuy, and Smith and Nephew ${ }^{26}$

2011: FDA writes to about 20 manufacturers to say that it is requiring post-marketing studies in cases where an implant's failure could have serious consequences. Companies would be expected to take blood samples from patients to measure metal ions.

2011: National Joint Register describes large diameter metal-on-metal and resurfacing prostheses in some people as a "cause for concern"

2011 Trial comparing large diameter Birmingham hip replacement with conventional hip is terminated after 2 years. Metal ion levels were raised above the MHRA advised safety level $(7 \mu \mathrm{g} / \mathrm{L}$ ) in $20 \%$ of the metal-on-metal group and in one patient in metal-on-polyethylene group (who had a metal-on-metal implant on the contralateral side $)^{27}$

2012: At the annual American Academy of Orthopedic Surgeons conference manufacturers promote metal-on-metal products to the 40000 attendees

\section{Figure}




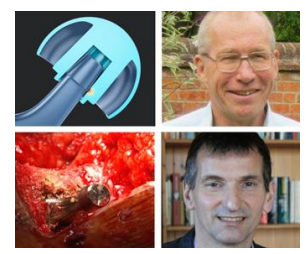

From left to right: Large diameter metal-on-metal hip implant highlighting wear pattern caused by toggling on models with short tapers; Chris Bulstrode, orthopaedic surgeon, Oxford University, tried to warn the Department of Health about overzealous innovation; Cobalt-chromium can release metal ions that can seep into local tissue causing reactions which destroy muscle and bone; Nick Freemantle, professor of clinical epidemiology: "We shouldn't be in this position where there's so much uncertainty" 